\title{
Unifying Biology Through Informatics (UBTI) a new programme of the International Union of Biological Sciences
}

\author{
David Peter Shorthouse ${ }^{\ddagger}$, David Patterson ${ }^{\S}$, Nils Chr. Stensethl \\ ‡ Canadian Museum of Nature, Ottawa, Canada \\ $\S$ University of Sydney, Sydney, Australia \\ I Centre for Ecological and Evolutionary Synthesis, University of Oslo, Oslo, Norway
}

Corresponding author: David Patterson (djpmapleferryman@gmail.com)

Received: 18 Aug 2017| Published: 18 Aug 2017

Citation: Shorthouse D, Patterson D, Stenseth N (2017) Unifying Biology Through Informatics (UBTI) a new programme of the International Union of Biological Sciences. Proceedings of TDWG 1: e20431. https://doi.org/10.3897/tdwgproceedings.1.20431

\begin{abstract}
Biological information, both new and old, is increasingly available in thousands of on-line sites. Biological information relates to elements as small as subatomic particles, and as large as the entire biosphere, and to processes that last from less than a femtosecond to many billions of years. Our economy, supply of food and materials, our health, and individual and collective well-being are set within the context of our natural world. Our world is under pressure from the demands of a growing population. Biologists need new ways to access, organize and analyze biological information to make new styles of research possible to better predict the nature of future change and to inform decisions makers. TDWG has promoted standardization that facilitates communication, but there is no overall architecture that interconnects the digital resources to better serve a wider community. The research funding paradigm leads to imaginative but competitive and short-lived enterprises. The Unifying Biology Through Informatics (UBTI) programme will explore the challenges that have to be overcome to add a cyberinfrastructure agenda to the current research agenda. An emerging infrastructure will require technical improvements inclusive of agreed metadata and ontologies to improve, extend and integrate the informatics tools, processes and skills to manage digital information across the full spectrum of biological phenomena.
\end{abstract}


The new tools must penetrate deep into a large number of small information sources. It will require co-operation of existing enterprises, a target of service not discovery, institutional support to guarantee long term funding of the emerging infrastructure, and a considerable financial investment. 'Unifying Biology Through Informatics' will articulate, in increasing detail, the nature of an indexing infrastructure capable of evolving in response to the needs of producers and users of data; the hosting, funding and sustainability of the infrastructure, and the political and social changes needed to secure the adoption, longevity, and use of the infrastructure. The programme welcomes input on selected use-cases that can be used to identify the most pressing challenges and opportunities.

\section{Keywords}

International Union of Biological Sciences, IUBS, biodiversity informatics, cyberinfrastructure, indexing

\section{Presenting author}

David Peter Shorthouse

\section{Funding program}

International Union of Biological Sciences

\section{Conflicts of interest}

None 